\title{
Implementation Intentions: The Mental Representations and Cognitive Procedures of If-Then Planning
}

Tanya S. Faude-Koivisto, Daniela Wuerz, and Peter M. Gollwitzer

\section{INTRODUCTION}

The cognitive processes that support and maintain goal pursuit have become a central issue among researchers studying self-regulation and motivation (Gollwitzer \& Bargh, 1994; Oettingen \& Gollwitzer, 2001; Shah \& Kruglanski, 2000; Sorrentino \& Higgins, 1986). Two key notions in self-regulation research on goals are the model of action phases (Gollwitzer, 1990; Heckhausen, 1991; Heckhausen \& Gollwitzer, 1987) and the concept of implementation intentions (Gollwitzer, 1993, 1996) as both address the complex interaction of cognitive and motivational processes. The model of action phases posits distinct consecutive stages of goal pursuit an individual has to successfully navigate to attain a goal and implies that self-regulation within each stage is facilitated by developing the respective mindset. On the other hand, implementation intentions (a concept stimulated by the action-phase model) are specific self-regulatory tools aimed at helping individuals plan and initiate goal-directed actions. A further self-rory tools process that has been identified to foster goal attainment is mental simulation (Escalas \& Luce, 2003, 2004; Greitemeyer \& Wuer2, 2006; Pham \& Taylor, 1999; Phillips \& Baumgartner, 2002 Taylor \& Pham, 1999). However, so far the cognitive processes associated with mental simulation have not been studied within the framework of the model of action phases or in comparison to implementation intentions.

The focus of this chapter is on expanding the existing theoretical and empirical framework of both the theoretical model of action phases and the concept of implementation intentions in two consecutive steps. First, implementation intentions and mental simulations (as two distinct selfregulatory tools) are contrasted in regard to their mode of cognitive functioning within the planning stage of goal pursuit. Second, basic cognitive properties of implementation intentions postulated to date are challenged and advanced in the light of the preceding comparison.

\section{THE MODEL OF ACTION PHASES AND RELATED MIND-SETS}

The model of action phases, providing a first comprehensive account of goal attainment, posits four different consecutive action phases of goal pursuit: the predecisional phase, the preactional phase, the actional phase, and the postactional phase (Gollwitzer, 1990; Heckhausen, 1991; Heckhausen \& Gollwitzer, 1987). In particular, the theory assumes that each phase is characterized 
by a distinct task that must be accomplished. The main task individuals have to solve in the first, predecisional phase, is to set a goal by making the best-possible choice between different wishes they entertain. To achieve this selection or prioritization, they weigh the pros and cons of their wishes on the basis of desirability and feasibility. Once a wish has been given the highest preference, individuals are ready to make a commitment to realize this wish (i.e., form a goal intention). If the perceived feasibility of realizing this wish is high and this expectation becomes activated (Oettingen, Pak, \& Schnetter, 2001; Oettingen \& Kappes, Chapter 26, this volume), people indeed form a strong goal intention. In the second, preactional phase, the main task is to plan the implementation of the chosen goal. Having formed a goal intention creates a feeling of commitment, prompting people to start planning and implementing respective goal-directed actions for goal attainment. Accordingly, individuals in this phase address questions of when and where to start acting, how to act, and how long to act. The transition from the preactional phase to the third, actional, phase is marked by action initiation. Individuals in the actional phase finally engage in activities to achieve their goals. Here, it becomes important to shield ongoing goal-directed activities from becoming derailed by distractions, difficulties, and hindrances. In the final, postactional phase, individuals have to solve the final task of evaluating the success of goal attainment.

The model of action phases implies that undertaking the four distinct tasks described activate congruent mind-sets (i.e., phase-typical cognitive procedures that promote successful task completion; Gollwitzer, 1990; see also Galinsky \& Kray, 2004). So far, a body of research has theoretically and empirically distinguished between deliberative and implemental mind-sets, that is, differences in cognitive processes when an individual is choosing a goal as compared to planning the attainment of a goal (summaries by Gollwitzer, 1990; Gollwitzer \& Bayer, 1999; Gollwitzer, Fujita, \& Oettingen, 2004)

\section{Deliberative and Implemental Mind-Sets: Empirical Support}

Research on the features of deliberative and implemental mind-sets has primarily looked at differences in regard to two cognitive procedures: cognitive tuning and biased inferences. Several studies exploring differences between the two mind-sets in cognitive tuning used the thought-sampling technique to demonstrate that a deliberative mind-set produces thoughts about expectancy-value issues, that is, thoughts focusing on aspects of goal feasibility and desirability (Heckhausen \& Gollwitzer, 1987; Puca \& Schmalt, 2001; Taylor \& Gollwitzer, 1995). On the other hand, thoughts of individuals in an implemental mind-set are focused on the when, where, and how of goal implementation. Using a cued-recall task, Gollwitzer, Heckhausen, and Steller (1990) found in addition that individuals in deliberative mind-sets process information on expectancy-value issues more effectively than individuals in implemental mind-sets, while individuals in implemental mind-sets process information on goal implementation more effectively than individuals in deliberative mindsets. These findings suggest that cognitive tuning in deliberative and implemental mind-sets is task congruous, that is, it is tuned toward thought contents that allow choosing between goals versus implementing a chosen goal, respectively.

Further, research on biased information processing suggests that individuals in a deliberative mind-set analyze information more impartially as their task is to choose between different wishes (i.e., they need to decide which wish is to be turned into a binding goal). Individuals in an implemental mind-set, on the other hand, tend to analyze information in a more partial way as they tend to look for information that justifies the goal choices made and thus supports goal implementation. Deliberating on one's wishes seems to activate even-handed processing of information that should benefit a good goal decision, while planning the implementation of a chosen goal, on the other hand, seems to activate partial processing of information to help defend the goal decision and protect it from questioning one's goal commitment (Armor \& Taylor, 2003; Gagne \& Lydon, 2001; Gollwitzer \& Kinney, 1989; Taylor \& Gollwitzer, 1995).

\section{Deliberative and Implemental Mind-Sets: Open-Mindedness to Information}

A further-suggested difference between deliberative and implemental mind-sets is openness to information. Gollwitzer (1990) argued that due to the different tasks associated with deliberative and implemental mind-sets (i.e., making a goal decision vs. implementing a chosen goal), individuals in a deliberative mind-set should be particularly open to any available information that might help them with the decision-making process (referred to as "general open-mindedness to information") When assessing desirability and feasibility, it seems beneficial to approach different pieces of information with a general open-mindedness because it is initially unclear which pieces of information are particularly relevant to the decision to be made. In contrast, individuals in an implemental mindset are primarily concerned with information about the when, where, and how of goal implementation. They process information more selectively, focusing on goal-relevant stimuli, while ignoring goal-irrelevant stimuli. As a result, a deliberative mind-set is associated with open-mindedness to information and an implemental mind-set with more closed-minded processing of information.

The suggested differences in open-mindedness between deliberative and implemental mindsets have been investigated by Fujita, Gollwitzer, and Oettingen (2007). In three studies, a deliberative mind-set led to superior recognition memory for incidental information than an implemental mind-set. For example, in Study 3, participants were either assigned to the deliberative mind-set, the implemental mind-set, or a control condition. After the mind-set manipulation, all participants had to perform a computerized concentration test. Randomly during the test, participants were presented with incidental words (e.g., bone, every, flag, always). After filling out various questionnaires, participants were asked to perform a surprise computerized recognition memory test containing the initially presented incidental words. Participants in the deliberative mind-set performed significantly better on the recognition memory test than those in the implemental mind-set and the control conditions, indicating that deliberative mind-sets are marked by more open-minded processing of available information than implemental mind-sets. As in all mind-set research, the Fujita et al. studies used unrelated tasks to instigate deliberative versus implemental mind-sets (i.e., deliberating the pros and cons of an unresolved personal problem vs. planning out the implementation of a chosen personal project, respectively). So, all of the incidental words were unrelated to the mind-set induction, and the findings can be confidently interpreted as mind-set effects rather than mere task-set effects.

\section{IMPLEMENTATION INTENTIONS: A STRATEGY FOR}

\section{EFFECTIVE SELF-REGULATION OF GOAL PURSUIT}

A development in intention-behavior relations is Gollwitzer's $(1993,1996,1999)$ concept of implementation intentions, a concept stimulated by the action-phases model. Implementation intention are if-then plans aimed at helping people overcome self-regulatory problems in goal striving by successfully achieving the task they are confronted with in the preactional phase of goal pursuitpreparing the execution of actions that are instrumental to attaining the chosen goal. This form of planning is assumed to increase the likelihood of attaining one's objectives compared to the formation of a mere goal intention.

Whereas goal intentions specify what one wants to achieve (e.g., "I intend to reach Z!"), implementation intentions specify in advance when, where, and how one intends to achieve it (e.g., "If situation $X$ occurs, then I will initiate goal-directed behavior $Y$ !"). Forming an implementation intention first involves the identification of a response that will promote goal attainment (i.e., is instrumental) and second the anticipation of a critical situation (i.e., a particular place, object, person, or point in time; but also a critical inner state such as being irritated; Achtziger, Gollwitzer, \& Sheeran, 2008) to initiate that response. Finally, the specified cue is linked to the response in an if-then format. For instance, an implementation intention formed to reach the goal "to pursue a healthy lifestyle" would involve an appropriate behavior (i.e., "choosing green tea") 
and a suitable situational context (i.e., "being asked for one's order at a restaurant") and take the format of "If I am having dinner at a restaurant and I'm asked for my order of drinks, then I will choose green tea."

A wealth of research has demonstrated the beneficial effects of implementation intentions as a self-regulatory tool in goal attainment. For example, Gollwitzer and Schaal (1998) observed that participants who had formed an implementation intention in addition to a goal intention were able to solve more arithmetic problems despite being distracted by simultaneously shown film clips of advertisements, compared to participants who had only formed a goal intention. Implementation intentions have been shown to be effective in promoting infrequently performed behaviors (e.g. cancer screening; Sheeran \& Orbell, 2000) and daily-performed behaviors (e.g., supplement use; Sheeran \& Orbell, 1999), no matter whether self-report or objective measures of performance were taken (e.g., Gollwitzer \& Brandstätter, 1997; Milne, Orbell, \& Sheeran, 2002). The effects on goal attainment were shown among students, the general public, and clinical samples (e.g., Brandstätter, Lengfelder, \& Gollwitzer, 2001; Lengfelder \& Gollwitzer, 2001; Orbell, Hodgkins, \& Sheeran, 1997). To this end, a meta-analysis of 94 independent studies reported a medium-to-large effect size of implementation intentions (Gollwitzer \& Sheeran, 2006), and this was on top of the medium effect of goal intentions on goal attainment.

So far, two processes have been proposed to explain why implementation intentions benefit goal achievement, relating either to the anticipated situation (i.e., the if-part) or the goal-directed behavior (i.e., the then-part). As forming implementation intentions implies the selection of a critical future situation (i.e., a great opportunity, a difficult situation), the mental representation of this situation is assumed to become highly activated and hence more accessible (Gollwitzer, 1993, 1996, 1999). Forming an implementation intention involves the selection of a situation that is ripe for action, thereby rendering the critical situation salient. This idea implies that people process information about the critical situation in a highly proficient manner (Gollwitzer, 1993 Achtziger, Bayer \& Gollwitzer, 2008; Webb \& Sheeran, 2006). Therefore, compared to those who merely form a respective goal intention, people who form implementation intentions are assumed to exhibit increased sensitivity to the critical cue. Various experiments (for a summary, see Gollwitzer, 1999) demonstrated that participants holding implementation intentions were more likely to detect (e.g., Steller, 1992), remember (e.g., Gottschaldt, 1926; Witkin, 1950), and attend (e.g. Achtziger, Bayer \& Gollwitzer, 2008) to the critical situation compared to participants who had only formed goal intentions.

Implementation intentions have also been shown to benefit action initiation through processes of automatization (Gollwitzer, 1993, 1996). Gollwitzer (1993) argued that forming an implementation intention (i.e., linking a critical situation to an intended behavior in the form of an if-then plan) is a conscious act of will that effectively delegates control of behavior from the self to specified situational cues that directly elicit action (also described as strategic "delegation of control to situational cues"). Forming an if-then plan means that the person commits himself or herself in advance to acting as soon as certain contextual constraints are satisfied. Once the specified situation is encountered, action initiation should proceed swiftly and effortlessly, without requiring the person's conscious intent. Thus, the execution of a behavior specified in an implementation intention is assumed to exhibit features of automaticity such as immediacy, efficiency, and no conscious intent (Bargh, 1992, 1994; Moors \& De Houwer, 2006). The postulated automation of action initiation has been supported by the results of various experiments that tested immediacy (e.g., Gollwitzer \& Brandstätter, 1997, Experiment 3; Webb \& Sheeran, 2006); efficiency (e.g., Brandstätter et al., 2001; Lengfelder \& Gollwitzer, 2001); and the absence of conscious intent (e.g., Bayer, Achtziger, Gollwitzer, \& Moskowitz, in press; Sheeran, Webb, \& Gollwitzer, 2005; overview by Gollwitzer \& Sheeran, 2006). In sum, the facilitating effects of implementation intentions appear to be associated with enhanced accessibility of good opportunities to act (if-component) and with the automation of goal-directed responding (then-component).

\section{MENTAL SIMULATION AND IMPLEMENTATION INTENTIONS:}

\section{TWO DISTINCT SELF-REGULATION TECHNIQUES FOR GOAL STRIVING}

In addition to implementation intentions, there are other self-regulation techniques that lead to successful goal attainment, namely, mental simulations. Conceptually different from implementation intentions (i.e., linkages of cues and responses in an if-then format), mental simulations can best be described as "imitative mental representations of some event or a series of events" (Taylor \& Schneider, 1989). When planning via mental simulation, a desired end state is approached through exploration of possible paths to goal attainment. Taylor, Pham, Rivkin, and Armor (1998) call such mental simulations process simulations, that is, the process of goal attainment is imagined step by step. Similar to implementation intentions, the effects of mental simulation have been found to promote goal attainment in many different domains, such as academic achievement (Pham \& Taylor, 1999; Taylor \& Pham, 1999), improving health-related behavior (Greitemeyer \& Wuerz, 2006), and facilitating behavioral intentions in the consumer domain (Escalas \& Luce, 2003, 2004; Phillips \& Baumgartner, 2002). Why do process-focused mental simulations benefit goal achievement? Several studies have demonstrated that the beneficial effects of mental simulation on the achievement of desired outcomes is linked to enhanced levels of planning, that is, action plan formation (Escalas \& Luce, 2003, 2004; Rivkin \& Taylor, 1999). Thus, both mental simulation and implementation intentions further goal attainment through enhanced planning of goal-directed actions.

However, the way in which mental simulations benefit the planning process should differ from that furthered by implementation intentions. The planning process associated with a mental simulation is marked by exploration of possible means or paths to a goal (Oettingen, 2000; Oyserman \& James, Chapter 25, this volume), while the formation of an implementation intention leads to the selection of a critical situation, which is then linked to a goal-directed response. No research to date has compared the two self-regulation tools against each other to detect differences and commonalities. Addressing this question will help us to better understand the various ways in which people can self-regulate goal striving by planning.

In this section, we introduce four studies that compare the cognitive functioning of two distinct self-regulation tools: implementation intentions versus mental simulations. The first set of studies (Studies 1 and 2) explores differences in mind-sets induced by if-then plans versus mental simulation. The second set of studies (Studies 3 and 4 ) builds on the initial results and investigates activation levels of the underlying mental representations implicated by the different planning techniques.

\section{Research on Mind-Sets Induced by Implementation Intentions Versus Mental Simulation}

Does mental simulation versus forming an if-then plan activate different mind-sets? If-then plans and mental simulations have thus far been considered as self-regulatory techniques that further goal attainment in the preactional phase through enhanced planning of goal-directed activities. The mind-set associated with this stage of the model of action phases is an implemental mind-set (Gollwitzer, 1990). However, we postulate that an individual can switch on an explorative mind-set in the preactional phase when performing mental simulations. Empirical support for this assumption is provided by research on hindsight bias and counterfactual priming, which suggests that inducing a mental simulation mind-set results in generating and considering additional alternatives (Galinsky \& Kray, 2004; Hirt, Kardes, \& Markman, 2004; Hirt \& Markman, 1995; Kahneman \& Tversky, 1982; Markman, Lindberg, Kray, \& Galinsky, 2007; Wong, Galinsky, \& Kray, Chapter 11, this volume). For example, Markman et al. (2007) found that activating a mental simulation mind-set through additive counterfactual thinking enhanced performance on creative generation tasks and lead to more expansive information processing with broader conceptual attention. As mentioned, finding and considering alternatives should be associated with an open-minded processing of information. 
On the other hand, several studies have demonstrated that forming if-then plans tunes individuals' thoughts into the when, where, and how of goal implementation, a feature associated with an implemental mind-set (Fujita et al., 2007; Gollwitzer \& Bayer, 1999; Taylor \& Gollwitzer, 1995). Fujita et al. (2007) further argued that implemental less so than deliberative mind-sets are associated with openness to available information. An implemental mind-set, then again, is associated with filtering of information and selective processing of stimuli (e.g., Gollwitzer, 1990; Kuhl, 1984) Therefore, Studies 1 and 2 were aimed at testing two assumptions: Mental simulation induces an explorative mind-set associated with a more open-minded processing of information (i.e., considering various means for a given goal), whereas forming if-then plans induces an implemental mind-set associated with a more closed-minded processing of information (i.e., focusing on one particular means to a given goal)

To measure breadth of information processing, we asked participants to generate alternatives of situational opportunities and goal-directed responses. Situational cues and goal-directed responses are both considered as means to a goal and represent the two parts of an implementation intention, that is, the if-part and the then-part. The structure of an if-then plan was reflected in our studies, such that Study 1 targeted the anticipated situation specified in the if-component of the implementation intention, and Study 2 targeted the critical response specified in the then-component. The second study further included a cognitive load condition to (a) replicate previous findings showing that implementation intentions operate efficiently (e.g., Brandstätter et al., 2001, Studies 2 and 3) and (b) explore the effect of cognitive load on mental simulation.

In Study 1, undergraduate students were asked to adopt the goal "to do well in school" (Wuerz, Gollwitzer, \& Greitemeyer, 2007). Next, half of the participants listened to a tape-recorded mental simulation, describing three different scenarios beneficial to the given goal (i.e., reading a textbook and marking passages in it with a highlighter, taking notes on a notepad in a lecture, writing an essay on a laptop). Participants were instructed to visualize the described scenarios as vividly as possible. In sum, the three scenarios contained a total of five critical situational cues (i.e., highlighter, textbook, notepad, laptop, lecture). The other half of the participants were asked to adopt five implementation intentions in the service of the adopted goal. The assigned if-then plans contained the same five situational cues described as elements of the if-part of the plans (e.g., "If I sit in front of my textbook, then I will read every passage very carefully"). Finally, participants in the mental simulation and implementation intention conditions were seated in front of a computer and presented with the five situational cues. For each stimulus, they were asked to come up with as many alternatives as possible during a time period of $3 \mathrm{~min}$. At the same time, we measured the time of stimulus onset (i.e., the presentation of the situational cues on the computer screen) to the moment when participants first pressed a key on the keyboard to start typing in alternatives. Hence, our dependent variables consisted of the mean number of generated alternatives to the presented stimuli and mean reaction times.

Mental simulation participants created more possible alternatives for the presented situational cues than implementation intention participants. However, after presentation of the situational cues, implementation intention participants started typing in alternatives to the cues more quickly than did mental simulation participants. The conclusions of the reported results are twofold. First, the explorative mind-set induced by mental simulation seems to enhance open-mindedness in the sense of making it easier to generate alternatives to presented situational cues (see also Wong et al., Chapter 11, this volume). On the other hand, forming if-then plans seems to lead to a more closed-minded processing of information, as indicated by producing fewer alternatives. Second, we observed that if-then plans not only lead to an overall narrower focus but also lead to a stronger focus on the situation specified beforehand, indicated by implementation intention participants' shorter reaction times between stimulus onset (i.e., presentation of the situational cues) and their initial response (i.e., starting to type in alternatives for the presented cues). Overall, these results suggest that mental simulation seems to create an exploratory mind-set with associated open-mindedness, while if-then plans lead to an implemental mind-set with a more closed-minded focus on the situations specified in the if-part of the implementation intentions.
Study 2 targeted the then-component of an implementation intention (Wuerz et al., 2007) Besides replicating the previous results, we wanted to demonstrate that mental simulation leads to finding more possible goal-directed actions. Furthermore, we examined whether mental simulation would be affected by cognitive load. The procedure of this study was very similar to the previous one with the exception that participants had to generate their own mental simulations or implementation intentions (as opposed to listening to a prerecorded mental simulation or adopting assigned ifthen plans). The goal given to participants was "to study effectively for an upcoming exam." Mental simulation participants were asked to visualize three different self-generated scenarios of studying for an exam. To this end, mental simulation participants were provided with three general examples of scenarios they could visualize (e.g., summarizing passages of a textbook) but were then prompted to come up with their own scenarios. They were told to visualize each scenario for at least $1 \mathrm{~min}$. After each visualization, participants had to briefly summarize the content of their visualization. Accordingly, participants in the implementation intention condition were first provided with the same three examples of studying as mental simulation participants and were then asked to generate three different if-then plans related to this goal. Specifically, they were asked to specify when, where, and how they would study. Implementation intention participants.specified, for instance, "If I sit at home at my desk, then I will read my textbook carefully."

After the experimental manipulation, all participants were presented with three of the situational cues they had previously specified (e.g., textbook, desk, lecture material) on a computer screen. For each presented cue, they were asked to generate as many goal-directed responses (i.e., behaviors they considered as beneficial for the given goal in that particular situation) as possible. For example, if "desk" was one of the previously generated situations of a particular participant, the participant might have generated "writing, reading, concentrating" as different kinds of behaviors related to studying that the participant thought of performing at a desk (i.e., goal-related responses). The situational cues presented to participants differed for each participant as they were chosen from their individually created materials. As soon as they started working on the computer task, half of the participants in each condition were put under cognitive load by asking them to count the number of vowels presented to them over headphones.

Mental simulation participants generated more possible action words related to presented situational cues (i.e., the cues that were selected from the individual mental simulations or implementation intentions) than implementation intention participants. However, this effect was moderated by cognitive load: Mental simulation participants generated a higher number of action words than if-then plan participants only under cognitive load, while under no load both groups performed equally well. Evidently, the open-mindedness associated with the explorative mind-set activated by mental simulations was enhanced by the depletion of resources. The generation of more action words under no load than under load by if-then plan participants, on the other hand, indicates that the closed-mindedness associated with the activated implemental mind-set was enhanced by the load manipulation. It appears, then, that the explorative mind-set effects associated with mental simulation (open-mindedness) versus the implemental mind-set effects associated with forming implementation intentions (closed-mindedness) are enhanced when cognitive resources become scarce. As habitual behavioral and cognitive orientations are commonly unaffected by load, we take this finding to mean that the habitual cognitive orientation of the explorative mind-set associated with mental simulations is open-mindedness, whereas the habitual cognitive orientation of the implemental mind-set associated with forming implementation intentions is closed-mindedness.

\section{Research on the Activation of Mental Representations by} Implementation Intentions Versus Mental Simulations

In Studies 3 and 4, we compared the activation of the mental representations that underlie if-then plans and mental simulations. As indirect measures have become the norm to measure construct activation (e.g., Kruglanski et al., 2002; Marsh \& Landau, 1995; Shah \& Kruglanski, 2000), we 
used a lexical decision task. Specifically, we compared the activation of the mental representation of critical situational stimuli and goal-directed responses when mentally simulating or forming if-then plans. Study 3 focused on the if-component of an implementation intention, assessing the mental representation of the specified situation, whereas Study 4 focused on its then-component, assessing the mental representation of the goal-directed response. In both studies, assigned if-then plans and mental simulations were used to ensure that heightened accessibility would not be muddled by semantic relatedness between words.

On their arrival at the laboratory, Study 3 participants were asked to adopt the goal "to do well in school." Next, mental simulation participants had to listen to a tape-recorded mental simulation describing three scenarios beneficial to the given goal (i.e., highlighting important passages in a textbook with a highlighter, writing an essay on a laptop, writing notes on a notepad during class). Hence, the mental simulation contained a total of five critical situational cues (i.e., textbook, highlighter, laptop, essay, notepad). Implementation intention participants were asked to adopt two if-then plans related to the goal, each plan containing one of the five situational cues mentioned (e.g., "If I have a highlighter in my hand, then I will underline important passages in my lecture materials"). Implementation intention participants were presented with the remaining situational cues (i.e., the situational cues that were not contained in their if-then plans) through a "spelling test" to ensure equal exposure to the stimuli across conditions. This test contained the three situational cues plus misspelled words, and participants were asked to correct any misspelled words. Finally, all participants were seated in front of a computer screen to perform a lexical decision task that contained the five situational cues (i.e., textbook, highlighter, laptop, essay, notepad), five matched neutral words, and ten nonwords.

The lexical decision task yielded faster reaction times to critical situational cues for implementation intention participants than for mental simulation. Assuming that faster latencies reflect more activation (e.g., Anderson, 1983; Ratcliff \& McKoon, 1978), this result indicates that forming implementation intentions leads to higher activation levels for the situation words than mentally simulating. Additional analyses demonstrated that, among implementation intention participants, only those situation words that were part of an if-then plan showed higher activation levels, but not the situation words that were presented in the spelling test. Mental simulation participants demonstrated equal activation levels for all five situation words, but their overall activation levels were lower than those of implementation intention participants. Thus, implementation intention participants seemed to focus on the two situational cues contained in their implementation intentions, while mental simulation participants focused on all five situation words equally strongly.

The aim of Study 4 was to replicate these findings with regard to the then-component of an implementation intention. This time, we used the goal "to lead a healthy lifestyle." One half of the participants had to perform a mental simulation describing three different goal-directed actions related to the goal (i.e., climbing the stairs, cooking a healthy meal, exercising in the gym). The other half of the participants had to adopt three if-then plans containing the three goal-directed actions of the mental simulation in the then-part of the plan (e.g., "If I enter a multistory building, then I will climb the stairs instead of taking the elevator"). Next, participants had to perform a lexical decision task containing the three critical action words, three matched neutral words, and six nonwords.

Results of the lexical decision task indicated that participants who had formed if-then plans responded faster to the action words describing the target response than to the words describing a neutral response. On the other hand, mental simulation participants reacted only slightly faster to target words compared to neutral words. Thus, the results of the present study indicate that forming if-then plans also leads to a higher activation of the target response contained in the then-component (and not just to a heightened activation of the situational cue specified in the if-component, as observed in the previous study).

In sum, the findings of Studies 3 and 4 presented suggest that forming if-then plans leads not only to higher activation of specified situational cues, but also to higher activation of a previously specified behavioral response, as is observed for mental simulations that contain these situations and responses.

\section{IMPLEMENTATION INTENTIONS AS MENTAL CONSTRUCTS: RECENT FINDINGS}

The last two studies presented in the preceding section primarily addressed the question of whether implementation intentions and mental simulations are associated with different activation levels of the mental representations of relevant situations and responses. These results thus provide new insights about the basic cognitive properties that may underlie the beneficial effects of implementation intention formation per se. According to the present findings, formation of implementation intentions (i.e., if-then linkage of specified situations and goal-directed behaviors) leads to higher activation of the mental representations of both of an if-then plan's components (i.e., the situation and the goal-directed behavior) in comparison to the mental representation of respective components that have only been mentally simulated.

As mentioned, two component processes have so far been postulated and empirically supported to explain implementation intentions' effectiveness: heightened accessibility of the specified situation and automatic initiation of the goal-directed behavior. In other words, only one component of if-then plans, that is the specified situation, has been referred to and investigated on a cognitive level. Yet, the question of how the goal-directed behavior (i.e., the then-component) is mentally represented has received no theoretical analysis or empirical attention. Rather, hitherto research on the then-component of an implementation intention has been limited to a behavioral level, investigating the features of goal-directed behavior when being triggered by the specified situation. That is, the specified behavior within an implementation intention has been merely conceptualized as an automatic response to the stimulus cue without consideration of potential intervening mental processes.

Hence, the results reported above not only contribute to evidence that forming an if-then plan enhances activation of the if-component, but also constitute first evidence of the mental representation and heightened activation of the plan's then-component on implementation intention formation. It therefore seems plausible to argue that (a) two cognitive processes-the heightened activation of the if-component and then-component, respectively-underlie the beneficial effects of implementation intention formation; and (b) on formation of an implementation intention (i.e., linking the specified situation to the goal-directed response) both components (the if-component and the then-component) become activated at the same time. However, these conclusions are premature particularly as activation levels of the if-component and the then-component of implementation intentions were measured in two separate studies, and in each study, the if-then plans were formed in the service of a different goal.

Therefore, the following line of research (Faude, 2005) attempted a critical, more specific test of the hypothesis of the coactivation of implementation intentions' two components. Specifically, the following assumptions were made regarding the anticipated situation and the goal-directed behavior as elements of an implementation intention: (a) Both components are mentally represented as knowledge structures and become simultaneously highly activated on formation of the if-then plan; and (b) the heightened accessibility of both elements is a result of their superior status due to having been linked in an "if-then" format and the functional relation between the two components. Three studies tested these assumptions using lexical decision latencies to assess levels of activation.

\section{Forming If-Then Plans: Activation of Both Components?}

It was determined that the best method to preliminarily investigate the mental representation of implementation intentions' dual components was to compare the accessibility of the anticipated situation and the goal-directed behavior between participants who had been asked to form if-then plans (experimental condition) and participants who had been equally exposed to the situation and behavior words but had not formed a plan (yoked control condition). Based on Gollwitzer's (1993, 
1996) argument that the selection of an implementation intention's particular component leads to heightened activation, Study 1 used self-generated if-then plans.

Experimental participants were first asked to generate two self-relevant goals in given domains by completing the sentence "I want to ..." (e.g." "I want to improve my relationship" as an interpersonal goal). After generation of each goal, participants were asked to list four behaviors (e.g., "forgive") they thought of as beneficial for achieving their goal and then were asked to generate relevant situations (e.g., "conversation") in which they wanted to carry out the behaviors they had listed before. Finally, they were asked to form implementation intentions (four per goal) by formulating an "If ... then ..." plan using the previously generated behaviors and situations (e.g., "If I am disappointed in a conversation, then I will forgive!"). Control participants were yoked to experimental participants by being exposed to the situation and behavior words that the respective experimental participan had generated beforehand, this by asking them to work on word lists.

Next, a lexical decision was administered to measure the accessibility of implementation intentions' components. The lexical decision included the critical words (i.e., previously generated situations and goal-directed responses) and nonwords. Hence, the words used in the lexical decision task differed for each participant in the experimental condition. Within the yoked control condition, the words in the lexical decision task corresponded to the materials of the participant in the implementation intention condition to which they were yoked.

Participants who had generated if-then plans responded significantly faster to situation words and behavior words than participants in the yoked control condition who had not formed plans. Applying the standard assumption that faster latencies reflect more activation (e.g., Anderson, 1983 Ratcliff \& McKoon, 1978), the present findings indicate that linking a specified situation to a goaldirected behavior in an if-then format (i.e., forming an implementation intention) leads to enhanced activation of the mental representation of both components of the plan (i.e., the specified situation and the goal-directed behavior).

\section{Components of If-Then Plans: Coactivation Due to Their}

\section{Functional Relation and Superior Status}

The reasons behind conducting Study 2 were multifold. First, the aim was to replicate the findings of Study 1 by introducing assigned (vs. self-generated) implementation intentions. Introducing assigned plans allowed for testing of the hypothesis that the heightened accessibility of implementation intentions' components is due to the superior status of the anticipated situation and the goal-directed behavior on linking in an if-then format and not due to a generation effect of the components. Second, to further investigate the superior status hypothesis, Study 2 used the same basic design as Study 1 but was augmented in the following ways: An equifinal goal plan structure was used that included one goal only and six implementation intentions. According to conventional goal architecture, lateral relations within a goal system are assumed to be primarily inhibitory (Kruglanski et al., 2002; Shah, Kruglanski, \& Friedman, 2003). Introducing several lateral relations on a mean level allows for conservative testing of the accessibility of the mental representation of the plans' components. Further, a "goal-only" condition was added in which participants were assigned the same goal intention as participants in the implementation intention condition but were not assigned any plan. This allowed for addressing the question of whether holding a goal intention only might suffice to activate certain goal-facilitating situations and behaviors without the need of forming specific plans. Third, to provide more direct support for the argument that heightened activation of implementation intentions' components is based on a functional (and not merely semantic) relation between these components, semantically unrelated words were chosen for the if-parts and then-parts of the plans to be assigned.

The materials consisted of one goal intention (i.e., "becoming socially integrated") plus six corresponding if-then plans (e.g., "If I am at the gym, then I will introduce myself to a fellow student.") Each if-then plan contained two critical words for the lexical decision task that corresponded to the situation (e.g., "gym") and the goal-directed behavior (e.g., "introduce"). After assigning the goal to participants in the plan condition and goal-only condition, participants in the plan condition were asked to adopt the six plans by reading them and then filling in respective blanks (e.g., "If I am at the , then I will___ myself.'). Participants in the goal-only and control condition were presented with a word list that contained the situation and behavior words of the implementation intentions to ensure equal encoding of the critical words to be used in the lexical decision task across conditions. Finally the identical lexical decision task was introduced to all three conditions.

Forming assigned implementation intentions led to heightened activation of both its components (i.e., the specified situation and the goal-directed behavior), as indicated by shorter mean response times to the situation and behavior words for participants who had formed if-then plans (i.e., implementation intention condition) compared to participants who had not (i.e., goal-only and control participants). Further, response times to the critical words did not differ between the goalonly and the control conditions, and comparing response latencies between the different plans in the implementation intention condition revealed no significant differences.

Demonstrating the robustness of the previous findings (i.e., simultaneous activation of both components of if-then plans on having formed an implementation intention), this result was hereinafter referred to as the "plan activation effect." In particular, the results offer evidence that this effect is functional rather than semantic (as only semantically unrelated words were used). In addition, activation of if-then plans' components was found to be attributable to neither a generation effect of the components (as assigned implementation intentions were used) nor a goal activation effect (as reaction times between the goal-only condition and the control condition did not differ), indicating that the plan activation effect is a result of the superior status of the components of implementation intentions. The superior status is further supported by the fact that the plan activation effect was found within an equifinal goal system of one goal with several potentially reciprocal inhibiting, lateral relations on a means level (i.e., six implementation intentions). The one-goal, sixplans structure did not attenuate the response latency advantage of the specified situations and the goal-directed behaviors.

\section{Automaticity in Plan Activation}

The aim of Study 3 was to investigate if the effect of plan activation is based on a consciously controlled process (i.e., requiring cognitive resources) or rather due to an automatic process that is characterized by its crucial features of immediacy, efficiency (i.e., not requiring much cognitive resources), and lack of conscious intent (Bargh, 1994, 1996, 1997; Bargh \& Chartrand, 1999; Logan, 1992; Shiffrin \& Schneider, 1977). The findings of the two previous studies can so far be interpreted as the plan activation process displaying two characteristics of automaticity, namely, the lack of conscious intent (as the measure of activation consisted of an indirect measure, i.e., lexical decision) and immediacy (as higher activation of if-then plans' components could be observed from the onset of activation measurement). However, thus far it is unclear if the cognitive advantage of implementation intentions' components is contingent on the amount of available cognitive resources.

To address the question of automaticity in if-then plan activation, the lexical decision task in Study 3 was administered under mental load, and activation levels of if-then plans' components were compared between implementation intentions and goal-only subjects. Based on the design of Study 2 , in Study 3 high levels of cognitive load were induced by presenting the target words in the lexical decision with a background pattern (following Park, Hertzog, Kidder, Morrell, \& Mayhorn, 1997). The dual task consisted of participants having to remember how many different background patterns they saw simultaneously while making lexical decisions.

As predicted, a higher activation of implementation intentions' components was also found under conditions of high cognitive load, as indicated by shorter mean response times to the situation and behavior words in the implementation intention condition compared to the goal-only condition. ${ }^{1}$ Evidently, the plan activation effect is based on an automatic process that does not require cogni- 
tive resources. Taken together, the results of Study 3 (a) closely replicate the plan activation effect (i.e., coactivation of both implementation intentions' components on formation of such plans) found in Studies 1 and 2 and (b) show that this effect appears to fulfill the three criteria of automaticity: immediacy, lack of conscious intent, and efficiency (i.e., not requiring cognitive resources; Bargh, 1994, 1996, 1997; Bargh \& Chartrand, 1999; Logan, 1992).

\section{CONCLUSIONS AND IMPLICATIONS}

This chapter had two primary objectives. First, it contrasted implementation intentions and mental simulations (i.e., two planning strategies shown to enhance goal attainment) with respect to the associated mind-sets (i.e., implemental vs. explorative mind-set, respectively). Second, the mental representations activated by mental simulations versus implementation intentions were mapped out by investigating the mental representation of the critical situations and behaviors entailed.

At the outset of the chapter, the so far theoretical and empirical association of deliberative and implemental mind-sets with distinct action phases (i.e., the predecisional and the preactional phases, respectively) was questioned (Wuerz et al., 2007). According to the model of action phases, choosing a goal (in the predecisional phase) activates a deliberative mind-set, whereas planning the implementation of a goal (in the preactional phase) always activates an implemental mind-set. In contrast, we proposed a more flexible approach to the question of type of mind-set in the preactional phase. We postulated that becoming involved with planning the implementation of a chosen goal induces either an implemental or an explorative mind-set, depending on which planning technique (i.e., implementation intentions or mental simulations) is used. The results of two studies were consistent with this supposition.

In Studies 1 and 2, open- versus closed-minded information processing (as characteristic of differential mind-sets) for participants in a mental simulation condition or an implementation intention condition were investigated by having to generate different means to a goal (i.e., situational opportunities in Study 1 and goal-directed responses in Study 2). In both studies, participants in the mental simulation condition came up with more means compared to participants in the implementation intention condition. These results indicate that mental simulation induces an explorative mind-set (see also Markman et al., 2007; Wong et al., Chapter 11, this volume) associated with open-mindedness (a cognitive feature previously solely associated with the predecisional phase), whereas implementation intentions induce an implemental mind-set associated with closed-mindedness (so far the only cognitive feature associated with the preactional phase). Hence, according to these findings, an explorative and an implemental mind-set can be activated within the preactional phase of goal pursuit depending on what planning strategy (i.e., mental simulations or implementation intentions, respectively) an individual chooses to apply.

In addition, in Studies 1 and 2, reaction times from stimulus onset (i.e., appearance of situational cues on the computer screen to which participants were asked either to find alternative situations or to generate corresponding goal-directed behaviors) to the participants' initial pressing of the keyboard when generating means (i.e., situational opportunities or goal-directed responses) were measured. Implementation intention participants responded faster to the presented materials than did mental simulation participants. This finding was first of all interpreted as evidence of a stronger focus on previously specified means as part of forming implementation intentions as compared to engaging in mental simulations. Second, this result was construed as a possible indicator of the basic cognitive processes (i.e., activation levels of mental representations) that underlie the differential mind-sets induced by implementation intentions and mental simulations, respectively. To address this question, two further studies measured activation levels of implementation intentions' and mental simulations' respective mental representations via a lexical decision task. Forming implementation intentions was found to result in heightened activation of the mental representation of situational cues (Study 3) and behavioral responses (Study 4), compared to mental simulation participants. This result was interpreted as evidence that differential activation levels of the mental representations of implementation intentions and mental simulations underlie the distinct information-processing modes that these two self-regulation tools trigger (i.e., closed- versus open-mindedness, respectively)

The second line of research (Faude, 2005) presented in this chapter marks the first direct attempt to map out implementation intentions as knowledge structures (i.e., as cognitive representations of a specified situation and a goal-directed behavior linked in an if-then format) and the first direct test of simultaneous activation of the mental representation of both components of implementation intentions (i.e., the situational cue and the goal-directed response) on formation of such plans. In three studies, forming implementation intentions led to shorter response times on a lexical decision task for situation and behavior words (i.e., the if-components and then-components of the previously formed if-then plans), relative to neutral words and relative to a condition in which only a goal intention was activated. Implicating that the formation of an implementation intention (i.e., linking a situational cue and a goal-directed response in an if-then format) leads to a heightened coactivation of the mental representation of both its components, this finding was termed the plan activation effect.

Specifically, in Study 1, self-generation of if-then plans was found to result in heightened activation of both components (i.e., the cue and the response) compared to a condition in which no plans were generated. Studies 2 and 3 replicated the plan activation effect with assigned implementation intentions implying that the heightened activation is a result of a superior status of the if-component and then-component (as part of an if-then plan) and not due to a generation effect of the components. The superior status of the components of if-then plans was further supported by Studies 2 and 3 , in which it was demonstrated that (a) assigning (i.e., activating) a goal intention only, without corresponding plans, did not suffice to activate certain goal-facilitating situations and behaviors (rather, plan activation was contingent on assignment of implementation intentions in addition to an underlying goal intention); and that (b) the plan activation effect could be obtained under conditions of several plans competing for resources in the face of a shared goal. In addition, Studies 2 and 3 provided evidence that forming implementation intentions leads to heightened activation of the specified situation and the goal-directed behavior as a result of their functional relation (i.e., having been linked in an if-then format) rather than due to their semantic relation. Last, the results of Study 3 demonstrated that the plan activation effect could be reliably obtained under conditions of high cognitive load, implying that the activation of implementation intentions' components on forming an if-then plan is due to an automatic process that does not require cognitive resources.

Together, these three studies demonstrate the following cognitive features of the mental representation of the anticipated situation and the goal-directed behavior as components of an implementation intention: (a) Both elements are cognitively represented as knowledge structures; (b) the formation of an implementation intention (i.e., linking the cue and the response in an if-then format) enhances the coactivation of both components, thereby demonstrating a plan activation effect; (c) the heightened accessibility of implementation intentions' components is a result of an automatic process due to their superior status and a functional relation between the components due to having been linked in an if-then format. The originality of these findings resides in the fact that they provide initial insights into the most basic processes by which implementation intentions promote goal attainment.

\section{Planning via Implementation Intentions Versus Mental Simulations}

If implementation intentions and mental simulations both represent effective planning techniques that foster goal attainment, when is it advisable to use one or the other? Do both strategies lead to the same outcome (i.e., reaching one's goals) and are therefore interchangeable depending on, for example, a person's random or personal preference? Or, does the effectiveness of each planning strategy vary depending on the respective circumstances (e.g., temporal) after having set a goal? The personal preference argument seems plausible in light of research on individual differences 
in mind-set activation. For example, Hirt et al. (2004) found that the manipulation of a menta simulation mind-set is less successful in individuals with a high need for closure (i.e., the desire to establish a definite opinion about topics; Kruglanski \& Webster, 1996). This suggests that individuals high in need for closure-if given the choice between planning via if-then plans or menta simulation-would lean toward forming implementation intentions rather than mental simulation as the former creates an implemental mind-set associated with closed-mindedness, whereas the latter creates an explorative mind-set associated with open-mindedness.

However, based on the differences we found in information processing (i.e., closed- vs. openmindedness) between if-then planners and mental simulators, we also speculate about the differential effectiveness of if-then planning versus mental simulation depending on the kind of goal striving at issue. An explorative mind-set associated with mental simulation might be beneficial at the outset of striving for a chosen goal as it allows for an exploration of the best ways to achieve a desired goal. Openness to information on possible means should thus also be very helpful in the face of novel or complex goals (i.e., whenever a detailed elaboration of the problem space is needed; see Oettingen \& Kappes, Chapter 26, this volume). However, once a decision about the best path toward a goal has been made, the planning of goal-directed action should benefit more from thoughts about when where, and how to take the chosen path as it is done by forming implementation intentions. In othe words, in the preactional phase individuals might benefit from an explorative mind-set associated with mental simulation at the onset of planning goal-directed actions and when the implementation of novel and complex goals is demanded, but when it comes to finalizing one's plans, formation of implementation intentions seems to be the preferred strategy as the associated implemental mindset provides the necessary closed-mindedness.

Imagine that you adopted the goal to lead a healthy lifestyle and so far have not paid a lot of attention to your health. When trying to achieve this goal, you would initially benefit from an explorative mind-set that allows you to imagine possible options on how to go about it (e.g., exercise more, eat more vegetables, drink more water, get more sleep). Therefore, mentally simulating different courses of action toward goal attainment would give you a good idea of what routes are available and most likely beneficial to you (e.g., your professional duties might not allow you to get more sleep, but you could easily exercise more). Once you are clear on your options on how to achieve your goal, your planning process would then benefit from forming implementation intentions as this would enable you to focus and decide on how to exactly implement your chosen course of action (i.e., exercise more by taking the stairs instead of the elevator or going to your gym in the evenings). That is, you can now further ensure goal achievement by forming an implementation intention that links an anticipated cue with an identified response in an if-then format (e.g., "If I find myself standing in front of an elevator, then I will choose to walk up the stairs"). As a positive side effect, making such if-then plans frees cognitive capacity for other endeavors as the initiation of the preselected response does not necessitate conscious intent. Taken together, we suggest that mental simulation and implementation intentions benefit the process of goal striving at different points in time of striving for a chosen goal, and this is particularly true for novel and complex goals. An important avenue for future research will be to systematically explore this assumption. This could be done by experimentally manipulating the order of mental simulation and forming implementation intentions and assessing the amount and quality of attainment of simple versus complex goals. Alternatively, field studies using time-sampling methodologies could obtain people's planning-related thoughts and then determine whether those individuals who most successfully attained their goals first engaged in mental simulations and only thereafter formed implementation intentions and whether this is particularly true for goals that are novel and complex.

In conclusion, this chapter highlights insights into motivational phenomena (i.e., goals and their means) that follow from a cognitive perspective on motivation (Gollwitzer \& Bargh, 1996; Kruglanski, 1996; Shah \& Kruglanski, 2000; Shah et al., 2003). Investigating the cognitive processes (i.e., mind-sets and mental representations) related to forming implementation intentions and engaging in mental simulations allows for an understanding of how these two self-regulation techniques of goal striving promote goal attainment. The findings afford new empirical and theoretical insights into the current understanding of (a) the beneficial effects of planning on goal striving in general and (b) the functioning of mental simulations and implementation intentions in particular. Besides the primary significance of the present research to understanding the functioning of mental simulations and implementation intentions, it has vast implications for the understanding of successful striving for chosen goals.

\section{NOTE}

1. A load manipulation check revealed a decrease in accuracy performance and an increase in overeffects between the plan condition and the goal-only condition in Study 3 on accuracy of performance. Therefore, even though the study did not include a control condition to directly test the cognitive load manipulation, a sufficient and equal cognitive load manipulation is assumed for the plan and goal-only condition in Study 3 (for details, see Faude, 2005).

\section{REFERENCES}

Achtziger, A., Bayer, U. C., \& Gollwitzer, P. M. (2008). Comitting to implementation intentions: Attention and memory effects for selected situational cues. (Submitted.)

Achtziger, A., Gollwitzer, P. M., \& Sheeran, P. (2008). Implementation intentions and shielding goal striving from unwanted thoughts and feelings. Personality and Social Psychology Bulletin, 34, 381-393.

Anderson, J. R. (1983). The architecture of cognition. Cambridge, MA: Harvard University Press.

Armor, D. A. \& Taylor, S. E. (2003). The effects of mindset on behavior: Self-regulation in deliberative and implemental frames of mind. Personality and Social Psychology Bulletin, 29, 86-95.

Bargh, J. A. (1992). The ecology of automaticity: Towards establishing the conditions needed to produce automatic processing effects. American Journal of Psychology, 105, 181-199.

Bargh, J. A. (1994). The four horsemen of automaticity: Awareness, efficiency, intention, and control in social interaction. In R. S. Wyer, Jr. \& T. K. Srull (Eds.), Handbook of social cognition (2nd ed., pp. 1-40). Hillsdale, NJ: Erlbaum.

Bargh, J. A. (1996). Principles of automaticity. In E. T. Higgins \& A.. Kruglanski (Eds.), Social psychology: Handbook of basic principles (pp. 169-183). New York: Guilford Press.

Bargh, J. A. (1997). The automaticity of everyday life. In R. S. Wyer Jr. (Ed.), The automaticity of everyday life: Advances in social cognition (Vol. 10, pp. 1-61). Mahwah, NJ: Erlbaum

Bargh, J. A., \& Chartrand, T. L. (1999). The unbearable automaticity of being. American Psychologist, 54, $462-479$.

Bayer, U. C., Achtziger, A., Gollwitzer, P. M., \& Moskowitz, G. B. (in press). Responding to subliminal cues: Do if-then plans facilitate action preparation and initiation without conscious intent? Social Cognition.

Brandstätter, V., Lengfelder, A., \& Gollwitzer, P. M. (2001). Implementation intentions and efficient action initiation. Journal of Personality and Social Psychology, 81, 946-960.

Escalas, J. E., \& Luce, M. F. (2003). Process versus outcome thought-focus and advertising. Journal of Consumer Psychology, 13, 246-54.

Escalas, J. E \& Luce, M. F. (2004). Understanding the effects of process-focused versus outcome-focused thought in response to advertising. Journal of Consumer Research, 31, 274-285.

Faude, T. S. (2005). The mental representation of plans. Unpublished doctoral dissertation, University of Konstanz, Germany.

Fujita, K., Gollwitzer, P. M., \& Oettingen, G. (2007). Mindsets and pre-conscious open-mindedness to incidental information. Journal of Experimental Social Psychology, 43, 48-61.

Gagne, F. M., \& Lydon, J. E. (2001). Mind-set and close relationships: When bias leads to (in)accurate predictions. Journal of Personality and Social Psychology, 81, 85-96.

Galinsky, A. D., \& Kray, L. J. (2004). From thinking about what might have been to sharing what we know: The effects of counterfactual mind-sets on information sharing in groups. Journal of Experimental Social Psychology, 40, 606-618.

Gollwitzer, P. M. (1990). Action phases and mindsets. In E. T. Higgins \& R. M. Sorrentino (Eds.), Handbook of motivation and cognition: Foundations of social behavior (Vol. 2, pp. 51-92). New York: Guilford Press. 
Gollwitzer, P. M. (1993). Goal achievement: The role of intentions. In W. Stroebe \& M. Hewstone (Eds.), European review of social psychology (Vol. 4, pp. 141-185). New York: Wiley.

Gollwitzer, P. M. (1996). The volitional benefits of planning. In P. M.. Gollwitzer \& J. A. Bargh (Eds.), The psychology of action: Linking cognition and motivation to behavior (pp. 287-312). New York: Guilford Press.

Gollwitzer, P. M. (1999). Implementation intentions: Strong effects of simple plans. American Psychologist, $54,493-503$.

Gollwitzer, P. M., \& Bargh, J. A. (1994). The psychology of action: Linking cognition and motivation to behavior. New York: Guilford Press.

Gollwitzer, P. M., \& Bayer, U. C. (1999). Deliberative and implemental mind-sets in the control of action. In S. Chaiken \& Y. Trope (Eds.), Dual-process theories in social psychology (pp. 403-422). New York: Guilford Press.

Gollwitzer, P. M., \& Brandstätter, V. (1997). Implementation intentions and effective goal pursuit. Journal of Personality and Social Psychology, 73, 186-199.

Gollwitzer, P. M., Fujita, K., \& Oettingen, G. (2004). Planning and the implementation of goals. In R. Baumeister \& K. Vohs (Eds.), Handbook of self-regulation research (pp. 211-228). New York: Guilford Press.

Gollwitzer, P. M., Heckhausen, H., \& Steller, B. (1990). Deliberative and implemental mind-sets: Cognitive tuning toward congruous thoughts and information. Journal of Personality and Social Psychology, 59 1119-1127.

Gollwitzer, P. M., \& Kinney, R. F. (1989). Effects of deliberative and implemental mind-sets on illusion of control. Journal of Personality and Social Psychology, 56, 531-542.

Gollwitzer, P. M. \& Schaal, B. (1998). Metacognition in action: The importance of implementation intentions. Personality and Social Psychology Review, 2, 124-136.

Gollwitzer, P. M., \& Sheeran, P. (2006). Implementation intentions and goal achievement: A meta-analysis of effects and processes. Advances in Experimental Social Psychology, 38, 69-119.

Gottschaldt, K. (1926). Ueber den Einfluss der Erfahrung auf die Wahrnehmung von Figuren: 1. Ueber den Einfluss gehaeufter Einpraegung von Figuren auf ihre Sichtbarkeit in umfassenden Konfigurationen. Psychologische Forschung, 8, 261-317.

Greitemeyer, T., \& Wuerz, D. (2006). Mental simulation and the achievement of health goals: The role of goal difficulty. Imagination, Cognition, and Personality, 25, 239-251.

Heckhausen, H. (1991). Motivation and action. Heidelberg: Springer-Verlag.

Heckhausen, H., \& Gollwitzer, P. M. (1987). Thought contents and cognitive functioning in motivational versus volitional states of mind. Motivation and Emotion, 11, 101-120.

Hirt, E. R., Kardes, F. R., \& Markman, K. D. (2004). Activating a mental simulation mind-set through generation of alternatives: Implications for debiasing in related and unrelated domains. Journal of Experimental Social Psychology, 40, 374-383.

Hirt, E. R., \& Markman, K. D. (1995). Multiple explanations: A consider-an-alternative strategy for debiasing judgments. Journal of Personality and Social Psychology, 36, 384-409.

Kahneman, D., \& Tversky, A. (1982). The simulation heuristic. In D. Kahneman, P. Slovic, \& A. Tversky (Eds.), Judgment under uncertainty: Heuristics and biases (pp. 201-208). Cambridge, England: Cambridge University Press.

Kruglanski, A. W. (1996). Goals as knowledge structures. In P. M. Gollwitzer \& J. A. Bargh (Eds.), The psy chology of action: Linking cognition and motivation to behavior (pp. 599-618). New York: Guilford Press.

Kruglanski, A. W., Shah, J. Y., Fishbach, A., Friedman, A., Young Chun, W., \& Sleeth-Keppler, D. (2002). A theory of goal-systems. Advances in Experimental Social Psychology, 34, 331-378.

Kruglanski, A. W., \& Webster, D. M. (1996). Motivated closing of the mind: "Seizing" and "freezing." Psychological Review, 103, 263-283.

Kuhl, J. (1984). Volitional aspects of achievement motivation and learned helplessness: Toward a comprehensive theory of action control. In B. A. Maher (Ed.), Progress in experimental personality research (Vol. 13, pp. 99-171). New York: Academic Press.

Lengfelder, A., \& Gollwitzer, P. M. (2001). Reflective and reflexive action control in patients with frontal lobe lesions. Neuropsychology, 15, 80-100.

Logan, G. D. (1992). Attention and preattention in theories of automaticity. American Journal of Psychology, $105,317-339$.
Markman, K. D., Lindberg, M. J., Kray, L. J., \& Galinsky, A. D. (2007). Implications of counterfactual structure for creative generation and analytical problem solving. Personality and Social Psychology Bulletin, $33,312-324$.

Marsh, R. L., \& Landau, J. D. (1995). Item availability in cryptomnesia: Assessing its role in two paradigms of unconscious plagiarism. Journal of Experimental Psychology: Learning, Memory, and Cognition, $21,1568-1582$.

Milne, S., Orbell, S. \& Sheeran, P. (2002). Combining motivational and volitional interventions to promote exercise participation: Protection motivation theory and implementation intentions. British Journal of Health Psychology, 7, 163-184.

Moors, A., \& De Houwer, J. (2006). Automaticity: A theoretical and conceptual analysis. Psychological Bulletin, 132, 297-326.

Oettingen, G. (2000). Expectancy effects on behavior depend on self-regulatory thought. Social Cognition, $18,101-129$.

Oettingen, G., \& Gollwitzer, P. M. (2001). Goal setting and goal striving. In A. Tesser \& N. Schwarz (Eds.), Blackwell handbook in social psychology: Intraindividual processes (Vol. 1, pp. 329-347). Oxford, England: Blackwell.

Oettingen, G., Pak, H., \& Schnetter, K. (2001). Self-regulation of goal setting: Turning free fantasies about the future into binding goals. Journal of Personality and Social Psychology, 80, 736-753.

Orbell, S., Hodgkins, S., \& Sheeran, P. (1997). Implementation intentions and the theory of planned behavior. Personality and Social Psychology Bulletin, 23, 945-954.

Park, D. C., Hertzog, C., Kidder, D. P., Morrell, R. W., \& Mayhorn, C. B. (1997). Effect of age on event-based and time-based prospective memory. Psychology and Aging, 12, 314-327.

Pham, L. P., \& Taylor, S. E. (1999). From thought to action: Effects of process-versus outcome-based mental simulations on performance. Personality and Social Psychology Bulletin, 25, 250-260.

Phillips, D. M., \& Baumgartner, H. (2002). The role of consumption emotions in the satisfaction response. Journal of Consumer Psychology, 13, 243-252.

Puca, R. M., \& Schmalt, H. D. (2001). The influence of the achievement motive on spontaneous thoughts in pre- and post-decisional action phases. Personality and Social Psychology Bulletin, 27, 302-308

Ratcliff, R., \& McKoon, G. (1978). Priming in item recognition: Evidence for the propositional structure of sentences. Journal of Verbal Learning and Verbal Behavior, 17, 403-417.

Rivkin, I. A \& Taylor, S. E. (1999). The effects of mental simulation on coping with controllable stressful events. Personality and Social Psychology Bulletin, 25, 1451-1462.

Shah, J., \& Kruglanski, A. (2000). Aspects of goal networks: Implications for self-regulation. In M. Boekaerts, P. Pintrich, \& M. Zeidner (Eds.), Handbook of self-regulation (pp. 85-110). San Diego, CA: Academic Press.

Shah, J. Y., Kruglanski, A. W., \& Friedman, A. (2003). Goal systems theory: Integrating the cognitive and motivation aspects of self-regulation. In S. Spencer, S. Fein, M. Zanna, \& J. Olson (Eds.), Motivated social perception: The Ontario symposium (pp. 247-275). Mahwah, NJ: Erlbaum.

Sheeran, P. \& Orbell, S. (1999). Implementation intentions and repeated behavior: Augmenting the predictive validity of the theory of planned behavior. European Journal of Social Psychology, 29, 349-369.

Sheeran, P., \& Orbell, S. (2000). Using implementation intentions to increase attendance for cervical cancer screening. Health Psychology, 19, 283-289.

Sheeran, P., Webb, T. L., \& Gollwitzer, P. M. (2005). The interplay between goal intentions and implementation intentions. Personality and Social Psychology Bulletin, 31, 87-98.

Shiffrin, R. M., \& Schneider, W. (1977). Controlled and automatic human information processing: II. Perceptual learning, automatic attending, and a general theory. Psychological Review, 84, 127-190.

Sorrentino, R. M., \& Higgins, E. T. (1986). Handbook of motivation and cognition (Vol. 1): Foundations of social behavior. New York: Guilford Press.

Steller, B. (1992). Vorsaetze und die Wahrnehmung guenstiger Gelegenheiten. Munich: Tuduv Verlagsgesellschaft.

Taylor, S. E., \& Gollwitzer, P. M. (1995). Effects of mindset on positive illusions. Journal of Personality and Social Psychology. 69, 213-226.

Taylor, S. E., \& Pham, L. B. (1999). The effect of mental simulation on goal-directed performance. Imagination, Cognition, and Personality, 18, 253-268.

Taylor, S. E., Pham, L. B., Rivkin, I. D., \& Armor, D.A. (1998). Harnessing the imagination: Mental simulation, self-regulation, and coping. American Psychologist, 53, 429-439. 
Taylor, S. E., \& Schneider, S. K. (1989). Coping and the simulation of events. Social Cognition, 7, 174-194. Webb, T. L., \& Sheeran, P. (2006). Does changing behavioral intentions engender behavior change? A metaanalysis of the experimental evidence. Psychological Bulletin, 132, 249-268.

Witkin, H. A. (1950). Individual differences in ease of perception of embedded figures. Journal of Personality, 19, $1-15$.

Wuerz, D. Gollwitzer, P. M., \& Greitemeyer, T. (2007). Mental simulation and implementation intentions: Initiating different mind-sets. Unpublished manuscript. 